\title{
HIV screening in men and women in Senegal: coverage and associated factors; analysis of the 2017 demographic and health survey
}

Ndeye Aïssatou Lakhe ${ }^{1 *} \mathbb{D}$, Khardiata Diallo Mbaye ${ }^{1}$, Khadime Sylla $^{2}$ and Cheikh Tidiane Ndour ${ }^{1,3}$

\begin{abstract}
Background: Despite the adoption of the provider-initiated HIV testing strategy, the rate of HIV testing is still very low in sub-Saharan Africa. The aim of this study was to assess the factors associated with HIV testing among sexually active women and men in Senegal. Knowledge of HIV status is the gateway to antiretroviral treatment.

Methods: A secondary analysis of the 2017 Senegal Demographic and Health Survey (DHS) was performed, using data on sexually active women aged 15-49 and men aged 15-59. The outcome variable was the proportion of women and men who reported ever being tested for HIV in the last 12 months before the survey. Descriptive, bivariate, and multivariable logistic regression analyses were performed to identify the socio-demographic, HIVknowledge, media exposure, and behavioral factors associated with HIV testing in Senegal.

Results: The study found that $61.1 \%$ (95\%Cl: 59.2-62.9) of women and $26.2 \%$ (95\%Cl: $24.2-28.3)$ of men were tested for HIV at the last 12 months. In multivariate analysis, among men the factors independently associated with being tested for HIV were: age groups 20-24 to 40-44 and age group 50-54; a higher level of education; being in the richest household wealth quintile; being married; knowing about the efficacy of HAART during pregnancy; having 2 or more lifetime sex partners and owning a mobile phone. Among women factors independently associated with HIV testing were: being in any age groups versus 15-19; a higher level of education; being in the richest household wealth quintile; being married; knowing about the efficacy of HAART during pregnancy; having any STI in last 12 months; fearing stigma; owning a mobile phone; and having any number of ANC visits, versus none.

Conclusion: Although HIV remains a public health threat, HIV testing's prevalence is still low in Senegal, making it difficult to interrupt the transmission chain within the community and to reach the UNAIDS goal for 2020 of "9090-90". Innovative community-based strategies are needed to address barriers and improve access to HIV testing in Senegal, particularly for men and for the youngest and poorest populations.
\end{abstract}

Keywords: HIV, Screening, Associated factors, Senegal

\footnotetext{
* Correspondence: aissatou.lakhe@ucad.edu.sn

${ }^{1}$ Clinic of Infectious and Tropical Diseases, Fann National University Hospital,

PO: 5035-Fann, Dakar, Sénégal

Full list of author information is available at the end of the article
}

(c) The Author(s). 2019 Open Access This article is distributed under the terms of the Creative Commons Attribution 4.0 International License (http://creativecommons.org/licenses/by/4.0/), which permits unrestricted use, distribution, and reproduction in any medium, provided you give appropriate credit to the original author(s) and the source, provide a link to the Creative Commons license, and indicate if changes were made. The Creative Commons Public Domain Dedication waiver (http://creativecommons.org/publicdomain/zero/1.0/) applies to the data made available in this article, unless otherwise stated. 


\section{Background}

Despite significant progress in recent decades, the HIV epidemic is still a major public health threat worldwide, with an estimated 37 million persons living with HIV in 2017, including 1.8 million children. Africa bears the heaviest burden, with more than 25 million people affected [1]. In Senegal, the AIDS response has achieved notable success since the first case was diagnosed in 1986 , with a low and stable prevalence of $0.4 \%$ in adults age 15-49 [1], a steady decline in new infections as well as in HIV-related deaths, and a significant increase of $57 \%$ in antiretroviral therapy coverage in 2017 [2]. In Senegal, HIV is a female epidemic, with a prevalence of $0.5 \%$ in women versus $0.4 \%$ in men [3].

The significant advances related to the adoption of early antiretroviral treatment from diagnosis [4] justify the ambitious goal set by the UNAIDS to reach the target of three 90 s for 2020 -meaning $90 \%$ of people with HIV are aware of their HIV status, $90 \%$ of those are on antiretroviral therapy, and $90 \%$ of those are virally suppressed [5]. UNAIDS predicts that reaching these targets by 2020 would enable the world to end the AIDS epidemic by 2030 [6]. In Senegal, the "Test All, Treat All and Retain in Senegal" strategy, called TATARSEN, was implemented in 2016 and was scaled up at the national level in 2017.

Awareness of HIV testing is key enabling initiation of early treatment and allowing the reduction of HIVrelated morbidity and mortality as well as the interruption of the transmission chain. In 2017, however, 25\% of all people living with HIV worldwide did not know their HIV status, corresponding at about 9.4 million people living with HIV but unaware of their serological status [1]. The challenge is to increase access to and uptake of HIV testing services (HTS) for those who remain undiagnosed and for those at greatest ongoing risk for HIV infection [6].

In Senegal, Law No. 2010-03 of 9 April 2010 on HIV/ AIDS sets the conditions for HIV screening using rapid diagnostic tests (RDTs) even at the health post level and which must be offered anonymously and free of charge. The current strategy is based on voluntary individual testing initiated by patients or care providers [2]. Despite all the progress made, Senegal is still very far from achieving the 2020 target of $90 \%$ of people with HIV being aware of their HIV status, with only $69 \%$ of person living with HIV diagnosed [2].

In the literature, HIV test uptake was found associated with several individual factors, including age and gender-young people are less likely to seek HIV testing [79], while females are more likely to be tested [9-11]. Another factor is person's sexual orientation and behavior [1, 12-15]. Other identified key factors correlated with HIV testing include area of residence [7, 13], level of education $[7,9,10]$, and knowledge of $\operatorname{HIV}[7,8,13,16$, 17]. Also, stigma and discrimination, whether perceived or experienced, has been identified as a real barrier to access to HIV testing services [7, 17, 18].

To date, no major study of HIV testing has been carried out at the national level in Senegal, and little is known about the correlates of HIV testing. Identifying the factors associated with HIV testing is a critical step in guiding the Senegalese AIDS program to develop policies and strategies, improve progress toward the first UNAIDS 90 indicator and reach the 2020 target. This study assesses factors associated with HIV testing among sexually active women and men in Senegal to better guide screening strategies in the country A conceptual framework has been developed for HIV testing after a literature review and analysis of associated factors. This conceptual framework is illustrated in Fig. 1.

\section{Methods}

\section{Data sources}

The main data source used was the 2017 Senegal Demographic Health Survey (DHS), which is a population-based nationally representative survey in which participants were selected using a two-stage stratified cluster sampling design according to DHS sampling methodology [19]. For the 2017 Senegal DHS, the following methodology was applied [3]: At the first stage, 400 clusters were selected independently with probability proportional to size from the list of enumeration areas (EAs) established during the 2013 General Census of Population and Housing, Agriculture and Breeding (RGPHAE). In the second stage, a sample of 22 households per cluster, both in urban and rural areas, was selected by equal probability systematic sampling. A total of 8800 households (4092 in urban areas and 4708 in middle rural) were selected. In each selected household, a questionnaire was completed to identify women age 15-49, men age 15-59, and children under age 5. Every eligible woman was interviewed with the DHS Woman's Questionnaire, and in those households selected for the men's interview, every eligible man was interviewed with the DHS Man's Questionnaire. These model questionnaires are developed by ICF and are used by several countries. The questionnaires are available in DHS website [20]. After finalizing the collection tools, the survey protocol and questionnaires of the 2017 Senegal Demographic Health Survey (DHS) were sent to the National Ethics Committee (CNERS) for analysis and approval. The CNERS authorized the investigation by the letter $\mathrm{N}^{\circ} 0035 \mathrm{MSAS} /$ DPRS/CNERS, of April 3, 2017. This survey also obtained the visa of the Committee of Ethics (Institutional Review Board) of ICF. Written informed 


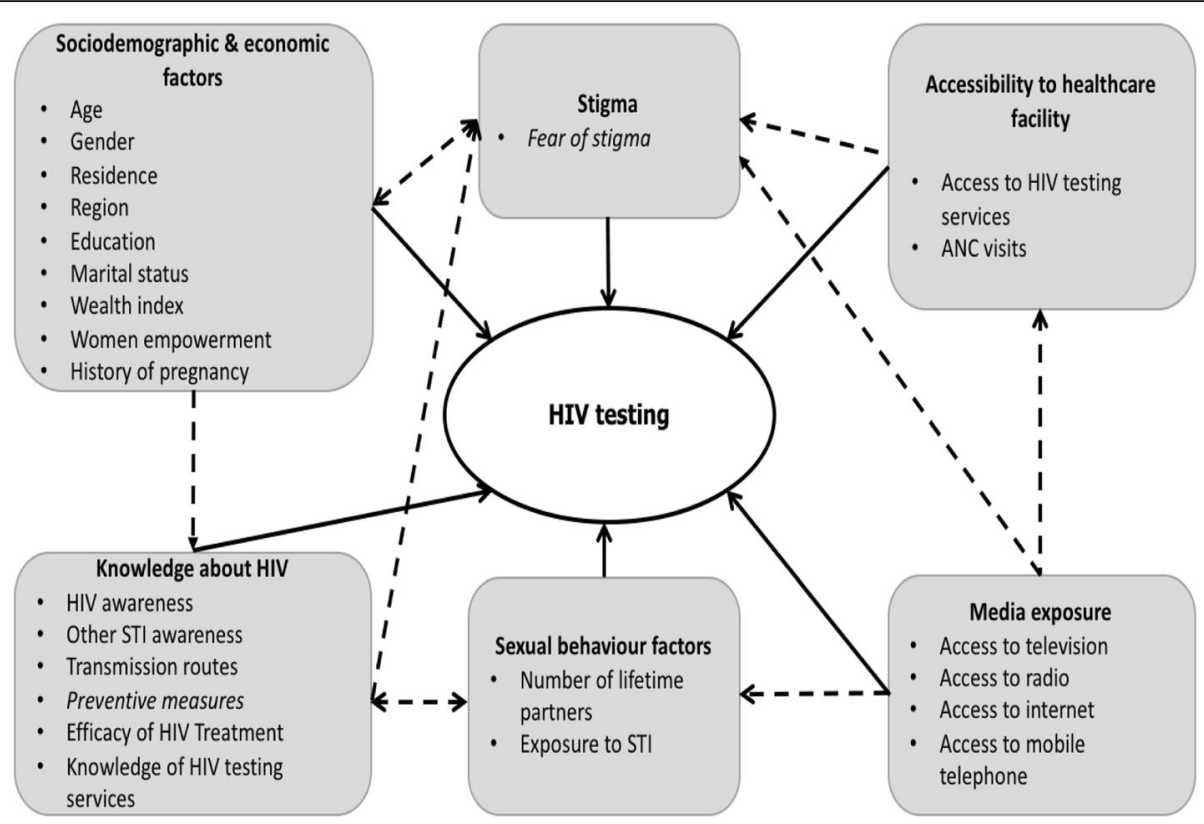

Fig. 1 Conceptual framework for HIV testing

consent was obtained from all participants prior to the administration of the questionnaires.

In our study, a secondary analysis of the Senegal 2017 DHS data was performed. Participants from urban and rural areas were selected from all the 14 administrative regions of Senegal. The study focused on sexually active women age 15-49 and men age 15-59. Participants who never had sex were excluded from the datasets, and accounted for 4167 in women and for 2451in men. After considering missing responses, the population size for our study was 12,205 women and 4414 men. The diagram flow of the population of study is represented in Fig. 2.

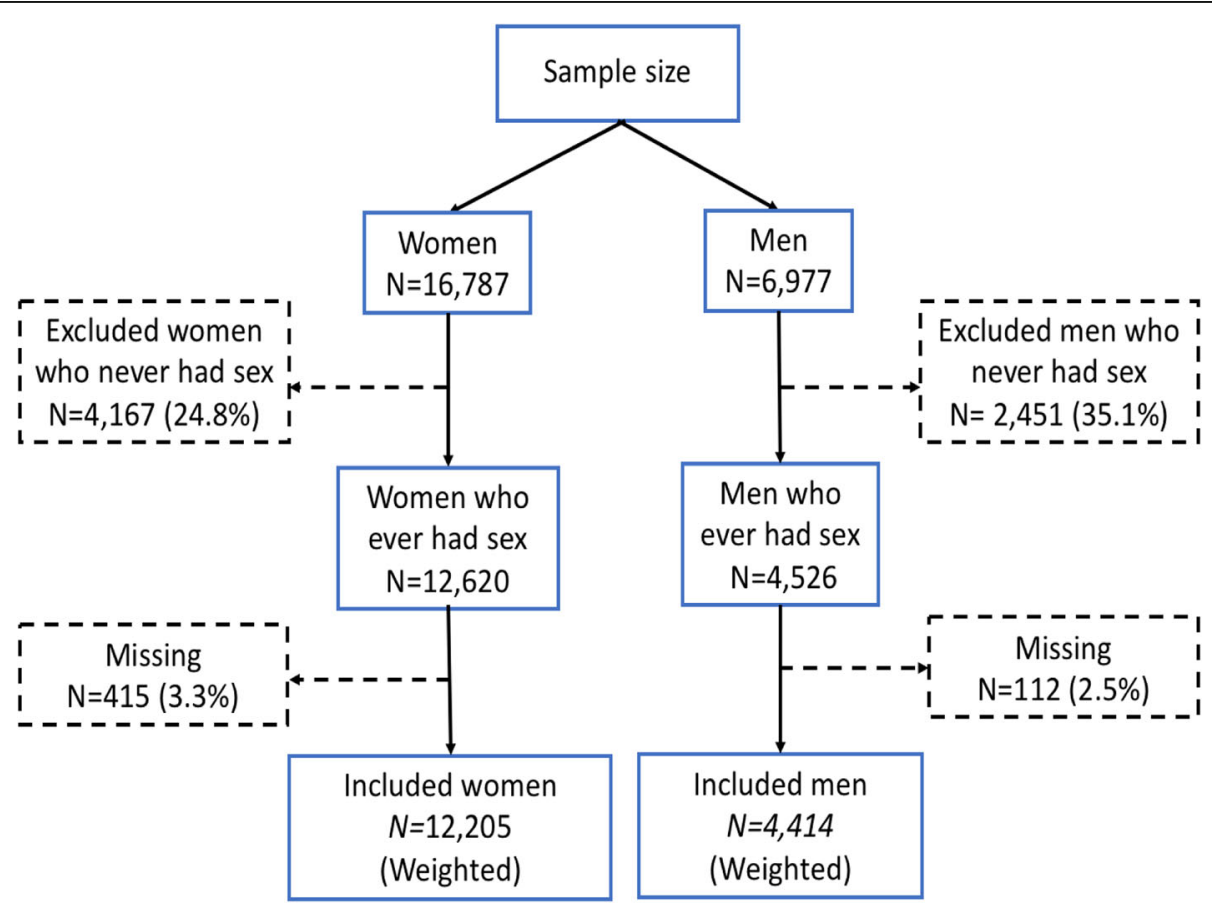

Fig. 2 Study population flow diagram 


\section{Outcome variable}

The outcome variable was: ever tested for HIV in the last 12 months. It was measured on the basis of responses to the survey question asked of sexually active men and women: "Have you ever been tested for HIV in the last 12 months?"

\section{Independent variables}

As shown in the conceptual framework, the study considered explanatory variables related to sociodemographic and economic factors, sexual behavior, HIV knowledge, stigma, media exposure, and antenatal care.

Socio-demographic and economic variables included: age (15-24, 25-29, 30-34, 35-39, 40-44, 45-49, 50-54, $55-59)$; wealth index in quintiles (poorest, poor, middle, rich, richest); and area of residence (urban, rural). Another related variable was residence, with the country's 14 administrative regions grouped in four geographic zones: West (Dakar, Thiès); North (Saint-Louis, Louga, Matam); Center (Diourbel, Fatick, Kaolack, Kaffrine); South-East (Tambacounda, Kedougou, Ziguinchor, Sedhiou, Kolda). For the analysis, the geographic zone was used rather than the administrative region. Others variables related to socio-demographic factors were: marital status (married, never been in union, divorced, widowed); and level of education (no education, primary, secondary, higher).

Factors related to sexual risk behaviors were: number of lifetime partners (1, 2 and more, don't know); and history of sexually transmitted diseases (STI) (had any STI in the last 12 months, "Yes/No"). Factors concerning knowledge of HIV were: sought knowledge of a place to get HIV test ("Yes/No"); knowledge about efficacy of highly active antiretroviral therapy (HAART) during pregnancy (taking drugs to avoid HIV transmission to baby during pregnancy, "Yes/No"); and knowledge about HIV and sexually transmitted infections (ever heard of STIs, ever heard of AIDS, knowledge about mother-tochild transmission of HIV). Participants were considered as having a good knowledge of mother-to-child transmission (MTCT) of HIV if they knew the three main transmission routes (pregnancy, delivery, breastfeeding).

To assess perceived HIV-related stigma, the variable was: "people hesitate to take HIV test because of the reaction of other people" ("Yes/No"). For media exposure, the variables were: access to the Internet ("Yes/No"); and ownership of a mobile phone ("Yes/No").

For women, an additional variable was considered: number of antenatal care (ANC) visits (none, 1 and more). The modality "none" included women who did not have a birth in the last 5 years as well as pregnant women who made no ANC visit.

\section{Statistical analysis}

The analysis was performed using STATA/SE 15.1 software. As stated above in the section on data source, a two-stage sampling design was adopted. To account for the survey's multi-stage sampling design, all data were weighted to adjust for disproportionate sampling and non-response. For women and men, individual weights were applied.

In the descriptive analysis, variables were presented in terms of the frequency and percentage of data for women and men. Intergroup comparisons were made using Chi2 test. The threshold of significance was set at 5 , and $95 \%$ confidence intervals $(\mathrm{CI})$ were considered.

To assess the factors associated with HIV testing, two adjusted logistic regressions analyses were performed for women and for men, and adjusted odds ratios (AOR) were calculated with their $95 \%$ confidence intervals. To address the complex sampling (multistage sampling, weighting and stratification), the weight, strata, and primary sampling units (PSU) identifier variables were set before using svy (STATA survey prefix) command. With the command svyset, for variance estimation, Taylor linearization was used. For women, we fit a logistic model of HIV testing with the following 12 independent variables: five-year age groups, zone, educational level, wealth quintile, marital status, knowledge of mother to child transmission of HIV, drugs to avoid HIV transmission to baby during pregnancy, had any STI in last 12 months, lifetime number of sex partners, self-stigma, mobile telephone ownership, and number of ANC visits. For men, a logistic model of HIV testing was fitted with the same independent variables as for women, except the number of ANC visits.

Collinearity was checked and some variables were excluded due to high collinearity with another variable. The variables "residence," "knowledge of a place to get HIV test", "television", "radio" and "use of Internet" were removed from both the models for women and men. For women, the variable "knowledge of a place to get HIV test" was removed because of empty cells, and collinearity was found between "residence" and "wealth class", and between "televison" and "wealth class". For men, "knowledge of a place to get HIV test" was removed because of empty cells, and collinearity was found between "residence" and "wealth class", and "use of Internet" and "educational level".

\section{Results}

\section{Background characteristics of the study population}

Table 1 summarizes the socio-demographic characteristics of women age 15-49 and men age 15-59 who were sexually active in the 12 months preceding the 2017 Senegal DHS. The greatest proportion of participants in both women and men were aged 30-34, with 19.7\% 
Table 1 Distribution of socio-demographic, economic and behaviorial characteristics, knowledge about HIV and others STIs, media exposure and stigma among women aged 15-49 and men aged 15-59 (weighted) [Senegal DHS, 2017]

\begin{tabular}{|c|c|c|c|c|c|c|}
\hline \multirow[t]{2}{*}{ Variables } & \multicolumn{3}{|l|}{ Women } & \multicolumn{3}{|l|}{ Men } \\
\hline & Percent (\%) & $95 \% \mathrm{Cl}$ & Number $(\mathrm{N})$ & Percent (\%) & $95 \% \mathrm{Cl}$ & Number $(\mathrm{N})$ \\
\hline \multicolumn{7}{|c|}{ Socio-demographic and economic characteristics } \\
\hline \multicolumn{7}{|c|}{ Age in 5-year groups } \\
\hline $15-19$ & 7.9 & $7.2-8.6$ & 964 & 5.5 & $4.8-6.4$ & 244 \\
\hline $20-24$ & 16.2 & $15.4-17.0$ & 1974 & 10.1 & $9.1-11.1$ & 446 \\
\hline $25-29$ & 19.5 & $18.7-20.3$ & 2377 & 14.5 & $13.1-16.1$ & 642 \\
\hline $30-34$ & 19.7 & 18.9-20.6 & 2407 & 16.4 & $15.1-17.8$ & 723 \\
\hline $35-39$ & 15.0 & $14.0-15.9$ & 1825 & 15.9 & $14.5-17.4$ & 703 \\
\hline $40-44$ & 12.7 & $12.0-13.5$ & 1555 & 11.2 & $10.2-12.4$ & 496 \\
\hline $45-49$ & 9.0 & $8.4-9.7$ & 1103 & 10.8 & $9.7-12.0$ & 478 \\
\hline $50-54$ & na & & na & 8.8 & $7.8-10.0$ & 389 \\
\hline $55-59$ & na & & na & 6.6 & $5.7-7.7$ & 293 \\
\hline \multicolumn{7}{|l|}{ Place of residence } \\
\hline Urban & 44.6 & $42.6-46.5$ & 5437 & 53.1 & $50.6-55.6$ & 2344 \\
\hline Rural & 55.4 & $53.5-57.4$ & 6767 & 46.9 & $44.4-49.4$ & 2071 \\
\hline \multicolumn{7}{|l|}{ Zone } \\
\hline West & 36.8 & $34.7-38.9$ & 4492 & 44.2 & $41.6-46.9$ & 1952 \\
\hline North & 16.8 & 15.6-18.1 & 2055 & 15.0 & $13.3-16.9$ & 661 \\
\hline Center & 27.9 & $26.5-29.4$ & 3,41 & 19.9 & $18.5-21.4$ & 879 \\
\hline South-East & 18.4 & $17.3-19.6$ & 2248 & 20.9 & $19.3-22.5$ & 923 \\
\hline \multicolumn{7}{|l|}{ Educational level } \\
\hline No education & 57.3 & $55.4-59.1$ & 6989 & 41.7 & $38.9-44.5$ & 1,84 \\
\hline Primary & 23.3 & 21.9-24.7 & 2839 & 25.1 & $23.0-27.3$ & 1107 \\
\hline Secondary & 16.3 & $15.2-17.4$ & 1983 & 24.4 & $22.4-26.5$ & 1076 \\
\hline Higher & 3.2 & $2.5-4.1$ & 393 & 8.8 & $7.0-11.2$ & 391 \\
\hline \multicolumn{7}{|l|}{ Marital status } \\
\hline Never in union & 4.9 & $4.2-5.6$ & 593 & 30.1 & $28.0-32.3$ & 1328 \\
\hline Married & 88.5 & $87.4-89.5$ & 10,8 & 67.7 & $65.4-69.9$ & 2,99 \\
\hline Widowed & 1.2 & $1.0-1.5$ & 146 & 0.3 & $0.2-0.5$ & 12 \\
\hline Divorced & 5.5 & $4.9-6.1$ & 666 & 1.9 & $1.4-2.5$ & 84 \\
\hline \multicolumn{7}{|l|}{ Never married } \\
\hline No & 95.1 & $94.4-95.8$ & 11,612 & 69.9 & $67.7-72.0$ & 3086 \\
\hline Yes & 4.9 & $4.2-5.6$ & 593 & 30.1 & $28.0-32.3$ & 1328 \\
\hline \multicolumn{7}{|l|}{ Wealth index } \\
\hline Poorest & 19.5 & $17.5-21.8$ & 2386 & 18.1 & $15.9-20.5$ & 800 \\
\hline Poorer & 19.6 & $17.9-21.5$ & 2397 & 17.1 & $15.4-19.0$ & 755 \\
\hline Middle & 20.3 & $18.2-22.4$ & 2473 & 19.1 & $16.8-21.7$ & 844 \\
\hline Richer & 19.7 & $17.7-21.9$ & 2407 & 22.1 & $19.4-25.1$ & 978 \\
\hline Richest & 20.8 & $18.5-23.4$ & 2542 & 23.5 & $20.5-26.8$ & 1038 \\
\hline \multicolumn{7}{|c|}{ Knowledge about HIV and STIs } \\
\hline \multicolumn{7}{|c|}{ Ever heard of a sexually transmitted infection (STI) } \\
\hline No & 3.4 & $3.0-4.0$ & 421 & 0.8 & $0.5-1.4$ & 37 \\
\hline Yes & 96.6 & $96.0-97.0$ & 11,784 & 99.2 & $98.6-99.5$ & 4378 \\
\hline
\end{tabular}

Ever heard of AIDS 
Table 1 Distribution of socio-demographic, economic and behaviorial characteristics, knowledge about HIV and others STIs, media exposure and stigma among women aged 15-49 and men aged 15-59 (weighted) [Senegal DHS, 2017] (Continued)

\begin{tabular}{|c|c|c|c|c|c|c|}
\hline \multirow[t]{2}{*}{ Variables } & \multicolumn{3}{|l|}{ Women } & \multicolumn{3}{|l|}{ Men } \\
\hline & Percent (\%) & $95 \% \mathrm{Cl}$ & Number (N) & Percent (\%) & $95 \% \mathrm{Cl}$ & Number (N) \\
\hline No & 3.7 & $3.2-4.3$ & 457 & 1.0 & $0.6-1.5$ & 43 \\
\hline Yes & 96.3 & $95.7-96.8$ & 11,748 & 99.0 & $98.5-99.4$ & 4371 \\
\hline \multicolumn{7}{|c|}{ Knowledge about mother-to-child transmission } \\
\hline No & 50.7 & $48.9-52.5$ & 6189 & 47.4 & $45.0-49.7$ & 2091 \\
\hline Yes & 49.3 & $47.5-51.1$ & 6016 & 52.6 & $50.3-55.0$ & 2324 \\
\hline \multicolumn{7}{|c|}{ Knowledge of a place to get HIV test } \\
\hline No & 19.9 & $18.4-21.4$ & 2424 & 37.0 & $34.4-39.6$ & 1632 \\
\hline Yes & 80.1 & $78.6-81.6$ & 9781 & 63.0 & $60.4-65.6$ & 2782 \\
\hline \multicolumn{7}{|c|}{ Taking drugs to avoid HIV transmission to baby during pregnancy } \\
\hline No & 52.1 & $50.0-54.2$ & 6354 & 45.7 & $43.2-48.2$ & 2016 \\
\hline Yes & 47.9 & $45.8-50.0$ & 5851 & 54.3 & $51.8-56.8$ & 2399 \\
\hline \multicolumn{7}{|l|}{ Sexual behavior } \\
\hline \multicolumn{7}{|c|}{ Had any STI in last 12 months } \\
\hline No & 96.7 & $96.2-97.1$ & 11,8 & 99.5 & $99.2-99.6$ & 4392 \\
\hline Yes & 3.3 & $2.9-3.8$ & 405 & 0.5 & $0.4-0.8$ & 23 \\
\hline \multicolumn{7}{|c|}{ Total lifetime number of sex partners } \\
\hline 1 & 80.8 & $79.7-81.8$ & 9859 & 29.5 & $27.5-31.6$ & 1302 \\
\hline $2+$ & 19.2 & $18.1-20.2$ & 2339 & 68.5 & $66.3-70.5$ & 3023 \\
\hline Don't know & 0.1 & $0.0-0.1$ & 7 & 2.0 & $1.6-2.6$ & 90 \\
\hline \multicolumn{7}{|l|}{ Fear of stigma } \\
\hline \multicolumn{7}{|c|}{ People hesitate to take HIV test because of the reaction of other people if positive } \\
\hline No & 22.2 & $20.7-23.8$ & 2708 & 22.5 & $20.7-24.3$ & 992 \\
\hline Yes & 77.8 & $76.2-79.3$ & 9497 & 77.5 & $75.7-79.3$ & 3423 \\
\hline \multicolumn{7}{|l|}{ Media exposure } \\
\hline \multicolumn{7}{|c|}{ Owns a mobile telephone } \\
\hline No & 29.3 & $27.6-31.0$ & 3572 & 6.4 & $5.6-7.3$ & 282 \\
\hline Yes & 70.7 & $69.0-72.4$ & 8633 & 93.6 & $92.7-94.4$ & 4133 \\
\hline \multicolumn{7}{|l|}{ Use of Internet } \\
\hline No & 76.9 & $75.0-78.7$ & 9385 & 58.0 & $55.4-60.6$ & 2561 \\
\hline Yes & 23.1 & $21.3-25.0$ & 2819 & 42.0 & $39.4-44.6$ & 1854 \\
\hline \multicolumn{7}{|c|}{ Numbers of ANC visits } \\
\hline None & 37.3 & $36.1-38.5$ & 4556 & na & na & na \\
\hline 1 & 2.5 & $2.2-2.9$ & 306 & na & na & na \\
\hline $2-3$ & 23.0 & $21.9-24.2$ & 2812 & na & na & na \\
\hline $4+$ & 37.1 & $35.9-38.4$ & 4,53 & na & na & na \\
\hline \multicolumn{7}{|c|}{ Ever been tested for hiv } \\
\hline No & 38.9 & $37.1-40.8$ & 4748 & 73.8 & $71.7-75.8$ & 3,26 \\
\hline Yes & 61.1 & $59.2-62.9$ & 7457 & 26.2 & $24.2-28.3$ & 1155 \\
\hline \multicolumn{7}{|c|}{ Received result from last hiv test } \\
\hline No & 41.9 & $40.1-43.7$ & 5116 & 5.8 & $4.5-7.4$ & 67 \\
\hline Yes & 58.1 & $56.3-59.9$ & 7089 & 94.2 & $92.6-95.5$ & 1088 \\
\hline Total & 100.0 & & 12205 & 100.0 & & 4415 \\
\hline
\end{tabular}


(95\%CI: $18.9-20.6)$ and $16.4 \%$ (95\%CI: $15.1-17.8)$ respectively. The majority of women (55.4\%; 95\%CI: 53.557.4) lived in rural areas, while more than a half of men (53.1\%; 95\%CI: 50.6-55.6) lived in urban ones.

Nearly six of every ten women (57.3\%; $95 \%$ CI: $55.4-$ 59.1) had no education versus four of every ten men (41.7\%; 95\%CI: 38.9-44.5). The proportion with education beyond the secondary level was low both among women (3.2\%; 95\%CI: $2.5-4.1)$ and men (8.8\%; 95\%CI: 7.0-11.2). Nearly nine of every ten women (88.5\%; $95 \%$ CI: 87.4-89.5) were married compared to two thirds among men (67.7\%; 95\%CI: 65.4-69.9).

Regarding the household wealth index, $45.6 \%$ of men were in the richer and richest quintiles versus $35.2 \%$ in the poorer and poorest quintiles. For women, the distribution by wealth quintile was more even, with $40.5 \%$ in the richer and richest quintiles versus $39.1 \%$ in the poorer and poorest quintiles.

Men had a slightly higher level of knowledge about HIV and sexually transmitted infections (STIs) than women (99.2\%; 95\%CI: 98.6-99.5 vs 96.6\%; CI95\%: 96.097.0). Surprisingly, awareness of mother-to-child transmission of HIV was also higher among men than women (52.6\%; $95 \%$ CI: $50.3-55.0$ vs $49.3 \%$; $95 \%$ CI: $47.5-51.1$ ), even though a higher proportion of women than men (80.1\%; 95\%CI: $78.6-81.6$ vs 63\%; 95\%CI: 60.4-65.6) knew a place to get an HIV test. Further, more than three quarters of both men (77.5\%; 95\%CI: 75.7-79.3) and women $(77.8 \%$; 95\%CI: $76.2-79.3)$ believed that people hesitate to take HIV test because of the reaction of other people if found HIV-positive.

Media exposure was higher for men, with 93.6\% (95\%CI: 92.7-94.4) owning a mobile phone versus $70.7 \%$ (95\%CI: 69.0-72.4) for women, and 42\% (95\%CI: $39.4-$ 44.6) of men having access to the Internet compared with $23.1 \%$ (95\%CI: $21.3-25.0$ ) of women.

Regarding the lifetime number of sex partners, nearly height out of ten women $(80.8 \%$; $95 \%$ CI: $79.7-81.8)$ had one while more than two thirds of men $(68.5 \%$; $95 \% \mathrm{CI}$ : 66.3-70.5) had two or more.

Among women, 37.1\% (95\%CI: 35.9-38.4) had four or more ANC visits for their most recent pregnancy while $37.3 \%$ (95\%CI: 36.1-38.5) had no birth during the past 5 years or did not attend ANC at all. The HIV testing rate in the 12 months before the survey was higher for women than men, at $61.1 \%$ (95\%CI: $59.2-62.9$ ) versus 26.2\% (95\%CI: $24.2-28.3)$.

\section{Bivariate analysis}

Table 2 presents the relationship between uptake of HIV testing and socio-demographic, economic, and behavioral characteristics, knowledge about HIV and other STIs, and media exposure among sexually active women age 15-49 and men age 15-59. For both women and men, uptake of HIV testing was significantly associated with the level of education. Those with a higher level were more likely to get tested. Similarly, regardless of gender, the HIV testing rate increased significantly with the level of household wealth, with the richest respondents being more likely to be tested with $74.2 \%(95 \% \mathrm{CI}$ : $70.9-77.4 ; p<0.001)$ for women and 40.1\% (95\%CI: $34.8-45.6 ; p<0.001)$ for men. Further, for both men and women, residing in an urban area or in the West zone was significantly associated with HIV testing.

HIV testing uptake was significantly associated with age only for women $(p<0.001)$, with adolescents (age 15-19) and young adults (age 20-24) less likely to be tested for HIV than adult women.

Others factors significantly influencing HIV testing were exposure to media, such mobile phone ownership $(p<0.001)$ or use of the Internet $(p<0.001)$ and, for women, the number of ANC visits $(p<0.001)$.

For women, marital status and lifetime number of sex partners were not significantly associated with the HIV testing rate, whereas for men, age, marital status, knowledge of mother-to-child transmission of HIV, and having any STI in the last 12 months were not associated with HIV testing.

\section{Factors associated with HIV testing}

Table 3 summarizes the results of the logistic regression analyses for women and men. In the multivariable analysis for women the following variables were significantly associated with being tested for HIV in the last 12 months: being in any age groups versus 15-19, high level of education; classification in the richest wealth quintile, married, knowledge about the efficacy of HART during pregnancy, any STI in the last 12 months; perceived HIV stigma (people hesitate to take HIV test because of the reaction of other people), ownership of a mobile phone, and number of ANC visits. Women in the North, were less likely to be tested compared with women in the West zone.

Among men, the following variables were significantly associated with being tested for HIV in the last 12 months: age groups $20-24$ to $40-44$ and age group 5054 , a higher level of education, classification in the richest wealth quintile, married, knowledge about the efficacy of HART during pregnancy, and ownership of a mobile phone. Unlike women, men in the North were more likely to be tested compared with men in the West zone.

\section{Discussion}

In Senegal, despite all the efforts made, the rate of HIV testing is still low, but shows a tendency to improve. Our study found that men have a better knowledge of HIV than women have, especially concerning the means 
Table 2 Association between HIV testing uptake and sociodemographic and economic characteristics', knowledge about HIV and STI, media exposure ad stigma among women aged 15-49 and men aged 15-59 [Senegal DHS, 2017]

\begin{tabular}{|c|c|c|c|}
\hline \multirow[t]{3}{*}{ Variables } & \multicolumn{3}{|c|}{ Ever been tested for HIV within 12 months } \\
\hline & Women (Yes) & & Men (Yes) \\
\hline & $\mathrm{Cl}$ & $p$-value & $p$-value \\
\hline
\end{tabular}

Age in 5-year groups

\begin{tabular}{|c|c|c|c|c|c|c|c|c|c|c|c|c|c|}
\hline \multirow[t]{3}{*}{ Variables } & \multicolumn{6}{|c|}{ Ever been tested for HIV within 12 months } & \multirow[t]{3}{*}{ Variables } & \multicolumn{6}{|c|}{ Ever been tested for HIV within 12 months } \\
\hline & \multicolumn{3}{|c|}{ Women (Yes) } & \multicolumn{3}{|c|}{ Men (Yes) } & & \multicolumn{3}{|c|}{ Women (Yes) } & \multicolumn{3}{|c|}{ Men (Yes) } \\
\hline & $\%$ & $\mathrm{Cl}$ & $p$-value & $\%$ & $\mathrm{Cl}$ & $p$-value & & $\%$ & $\mathrm{Cl}$ & $p$-value & $\%$ & $\mathrm{Cl}$ & $p$-value \\
\hline \multicolumn{7}{|c|}{ Age in 5-year groups } & \multicolumn{7}{|c|}{ Taking drugs to avoid HIV transmission to baby during pregnancy } \\
\hline $15-19$ & 34.2 & $30.5-38.2$ & $<0.001$ & 17.2 & $12.7-22.9$ & 0.076 & No & 52.7 & $50.4-55.0$ & $<0.001$ & 17.3 & $15.2-19.5$ & $<0.001$ \\
\hline $20-24$ & 59.9 & $56.7-63.1$ & & 22.5 & $18.0-27.8$ & & Yes & 70.2 & $68.1-72.3$ & & 33.6 & $30.8-36.6$ & \\
\hline $25-29$ & 67.6 & $64.9-70.1$ & & 27.5 & $22.7-32.9$ & & \multicolumn{7}{|c|}{ Knowledge of a place to get HIV test } \\
\hline $30-34$ & 68.8 & $66.1-71.3$ & & 27.7 & $23.2-32.8$ & & No & 0.0 & & $<0.001$ & 0.0 & & $<0.001$ \\
\hline $35-39$ & 66.3 & $63.1-69.4$ & & 27.7 & $23.5-32.3$ & & Yes & 76.2 & $74.7-77.7$ & & 41.5 & $38.7-44.4$ & \\
\hline $40-44$ & 59.1 & $55.6-62.6$ & & 27.2 & $22.0-33.2$ & & \multicolumn{7}{|c|}{ Had any STI in last 12 months } \\
\hline $45-49$ & 50.1 & $46.0-54.2$ & & 26.6 & $21.7-32.2$ & & No & 60.7 & $58.9-62.6$ & $<0.001$ & 26.2 & $24.2-28.3$ & 0.561 \\
\hline $50-54$ & na & na & & 30.8 & $24.2-38.4$ & & Yes & 71.8 & $66.3-76.6$ & & 21.6 & $10.4-39.4$ & \\
\hline $55-59$ & na & na & & 20.0 & $14.6-26.8$ & & \multicolumn{7}{|c|}{ Total lifetime number of sex partners } \\
\hline Zone & & & & & & & 1 & 60.8 & $58.8-62.9$ & 0.303 & 19.6 & $16.9-22.6$ & $<0.001$ \\
\hline West & 74.2 & $71.5-76.7$ & $<0.001$ & 29.4 & $25.7-33.5$ & $<0.01$ & $2+$ & 62.3 & $59.8-64.7$ & & 28.6 & $26.2-31.1$ & \\
\hline North & 46.4 & $41.2-51.7$ & & 25.7 & $22.0-29.9$ & & Don't Know & 33.3 & $5.4-81.5$ & & 39.3 & $29.4-50.1$ & \\
\hline
\end{tabular}

Table 2 Association between HIV testing uptake and sociodemographic and economic characteristics', knowledge about HIV and STI, media exposure ad stigma among women aged 15-49 and men aged 15-59 [Senegal DHS, 2017] (Continued)

Place of residence

$\begin{array}{lllllll}\text { Urban } & 70.6 & 68.4-72.7 & <0.001 & 32.5 & 29.3-35.9 & <0.001 \\ \text { Rural } & 53.5 & 50.7-56.2 & & 19.0 & 16.9-21.2 & \end{array}$

Educational level

No education $\quad 53.7 \quad 51.4-56.0 \quad<0.001 \quad 13.4 \quad 11.5-15.4<0.001$

$\begin{array}{lllll}\text { Primary } & 67.3 & 64.6-69.9 & 21.7 & 18.5-25.3\end{array}$

$\begin{array}{lllll}\text { Secondary } & 73.8 & 71.0-76.4 & 41.5 & 37.6-45.5\end{array}$

$\begin{array}{lllll}\text { Higher } & 84.2 & 77.8-88.9 & 56.7 & 49.0-64.1\end{array}$

Marital status

Never in union $\quad 55.8 \quad 50.4-61.2 \quad 0.105 \quad 25.9 \quad 22.6-29.6 \quad 0.296$

$\begin{array}{lllll}\text { Married } & 61.5 & 59.5-63.6 & 26.5 & 24.2-29.0\end{array}$

$\begin{array}{lllll}\text { Widowed } & 53.4 & 44.2-62.3 & 10.8 & 2.7-34.3\end{array}$

$\begin{array}{lllll}\text { Divorced } \quad 60.3 & 54.7-65.6 & 18.1 & 11.1-28.1\end{array}$

Never married

$\begin{array}{lllllll}\text { No } & 61.4 & 59.4-63.3 & 0.051 & 26.2 & 24.0-28.7 & 0.883 \\ \text { Yes } & 55.8 & 50.4-61.2 & & 25.9 & 22.6-29.6 & \\ \text { Nealth index } & & & & & & \\ \text { Poorest } & 42.3 & 38.6-46.2 & <0.001 & 11.6 & 9.2-14.6 & <0.001 \\ \text { Poor } & 52.0 & 48.4-55.6 & & 19.5 & 16.4-23.1 & \\ \text { Middle } & 64.6 & 61.8-67.3 & & 25.7 & 22.2-29.6 & \\ \text { Richer } & 71.3 & 68.5-74.0 & 28.7 & 24.6-33.2 & \\ \text { Richest } & 74.2 & 70.9-77.4 & 40.1 & 34.8-45.6 & \end{array}$

Knowledge about mother-to-child transmission

$\begin{array}{lllllll}\text { No } & 57.9 & 55.7-60.0 & <0.001 & 26.5 & 24.1-29.2 & 0.699 \\ \text { Yes } & 64.4 & 61.9-66.9 & & 25.8 & 23.0-28.8 & \end{array}$

People hesitate to take HIV test because of the reaction of other people if positive (Fear of stigma)

$\begin{array}{lllllll}\text { No } & 39.4 & 36.6-42.3 & <0.001 & 18.2 & 15.2-21.7 & <0.001 \\ \text { Yes } & 67.3 & 65.5-69.0 & & 28.5 & 26.1-30.9 & \end{array}$

Owns a mobile telephone

$\begin{array}{lllllll}\text { No } & 48.4 & 45.6-51.2 & <0.001 & 9.9 & 6.8-14.1 & <0.001 \\ \text { Yes } & 66.4 & 64.5-68.1 & & 27.3 & 25.2-29.4 & \end{array}$

Use of internet

$\begin{array}{lllllll}\text { No } & 56.2 & 54.1-58.3 & <0.001 & 15.6 & 14.0-17.5 & <0.001 \\ \text { Yes } & 77.4 & 74.9-79.8 & & 40.7 & 37.2-44.2 & \end{array}$

Numbers of ANC visit

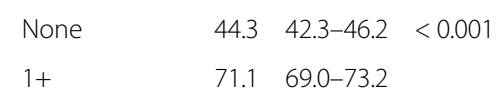

of transmission and treatment, and even concerning HIV transmission from mother to child. Despite having lower levels of HIV knowledge, women's HIV testing rates are much higher than for men, at $62 \%$ versus $27 \%$. This seems to be a constant finding across studies [9$11,21]$. It suggests that women have better access to health facilities through several programs devoted to them, such as reproductive health care services. Likely, HIV testing during ANC explains much of the difference between women and men. In fact, ANC visits are opportunities for women to benefit from having an HIV test. Strategies specifically targeting men should be developed in Senegal in order to catch up with women in HIV testing, such as encouraging women during antenatal care to have their partners seek testing. 
Table 3 Multivariable logistic model for correlates of HIV testing among sexually active women aged 15-49 and men aged 1559 in Senegal (DHS 2017)

\begin{tabular}{|c|c|c|c|c|}
\hline \multirow[t]{2}{*}{ Variables } & \multicolumn{2}{|c|}{ Women } & \multicolumn{2}{|l|}{ Men } \\
\hline & $\overline{A O R}$ & $95 \% \mathrm{Cl}$ & $\overline{A O R}$ & $95 \% \mathrm{Cl}$ \\
\hline \multicolumn{5}{|l|}{ Age in 5-year groups } \\
\hline $15-19$ & 1.0 & & 1.0 & \\
\hline $20-24$ & $2.0^{* * *}$ & $1.6-2.5$ & 1.3 & $0.8-2.0$ \\
\hline $25-29$ & $2.5^{* * *}$ & $2.0-3.1$ & $1.7^{*}$ & $1.0-2.7$ \\
\hline $30-34$ & $2.6^{* * *}$ & $2.0-3.2$ & $1.9^{*}$ & $1.1-3.3$ \\
\hline $35-39$ & $2.8^{* * *}$ & $2.2-3.5$ & $2.0^{*}$ & $1.1-3.3$ \\
\hline $40-44$ & $2.5^{* * *}$ & $1.9-3.2$ & $1.9^{*}$ & $1.1-3.1$ \\
\hline $45-49$ & $2.3^{* * *}$ & $1.7-3.1$ & 1.6 & $0.9-2.9$ \\
\hline $50-54$ & na & na & $2.1^{*}$ & $1.1-3.8$ \\
\hline $55-59$ & na & na & 1.1 & $0.6-2.1$ \\
\hline \multicolumn{5}{|l|}{ Zone } \\
\hline North & 1.0 & & 1.0 & \\
\hline West & $2.8^{* * *}$ & $2.2-3.6$ & $0.5^{* * *}$ & $0.4-0.7$ \\
\hline Center & $1.9^{* * *}$ & $1.5-2.4$ & $0.7^{*}$ & $0.5-0.9$ \\
\hline South-East & $2.1^{* * *}$ & $1.6-2.7$ & 0.8 & $0.6-1.1$ \\
\hline \multicolumn{5}{|l|}{ Educational level } \\
\hline No education & 1.0 & & 1.0 & \\
\hline Primary & $1.3^{* * *}$ & $1.1-1.4$ & $1.7^{* * *}$ & $1.3-2.2$ \\
\hline Secondary & $1.8^{* * *}$ & $1.5-2.1$ & $4.6^{* * *}$ & $3.5-5.9$ \\
\hline Higher & $1.9^{* *}$ & $1.3-2.9$ & $6.7^{* * *}$ & $4.6-9.9$ \\
\hline \multicolumn{5}{|l|}{ Wealth index } \\
\hline Poorest & 1.0 & & 1.0 & \\
\hline Poorer & $1.3^{* *}$ & $1.1-1.6$ & $1.6^{* *}$ & $1.1-2.2$ \\
\hline Middle & $2.0^{* * *}$ & $1.6-2.4$ & $2.0^{* * *}$ & $1.4-2.8$ \\
\hline Richer & $2.3^{* * *}$ & $1.8-2.9$ & $2.3^{* * *}$ & $1.6-3.4$ \\
\hline Richest & $1.8^{* * *}$ & $1.4-2.4$ & $2.4^{* * *}$ & $1.6-3.8$ \\
\hline \multicolumn{5}{|l|}{ Marital status } \\
\hline Never been in union & 1.0 & & 1.0 & \\
\hline Married & $1.6^{* *}$ & $1.2-2.1$ & $1.7^{* * *}$ & $1.3-2.3$ \\
\hline Widowed & 1.5 & $0.9-2.7$ & 0.9 & $0.2-3.6$ \\
\hline Divorced & 1.4 & $1.0-2.0$ & 0.8 & $0.4-1.4$ \\
\hline \multicolumn{5}{|c|}{ Knowledge about mother-to-child transmission } \\
\hline No & 1.0 & & 1.0 & \\
\hline Yes & 1.0 & $0.9-1.2$ & 0.8 & $0.6-1.0$ \\
\hline
\end{tabular}

Taking drugs to avoid HIV transmission to baby during pregnancy

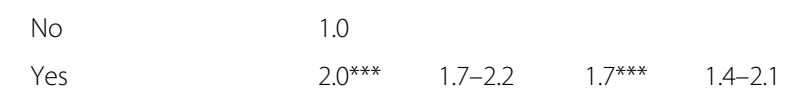

Had any STI in last 12 months

$\begin{array}{lllll}\text { No } & 1.0 & & 1.0 & \\ \text { Yes } & 1.4^{*} & 1.1-1.9 & 0.8 & 0.3-2.3\end{array}$

Total lifetime number of sex Partners
Table 3 Multivariable logistic model for correlates of HIV testing among sexually active women aged 15-49 and men aged 1559 in Senegal (DHS 2017) (Continued)

\begin{tabular}{llllll}
\hline Variables & \multicolumn{3}{l}{ Women } & & \multicolumn{2}{l}{ Men } \\
\cline { 2 - 3 } & AOR & $95 \% \mathrm{Cl}$ & & AOR & $95 \% \mathrm{Cl}$ \\
\hline $2+$ & 1.0 & $0.9-1.2$ & & $1.3^{*}$ & $1.0-1.7$ \\
Don't know & 1.0 & $0.1-18.0$ & & $2.0^{*}$ & $1.1-3.5$
\end{tabular}

People hesitate to take HIV test because of the reaction of other people

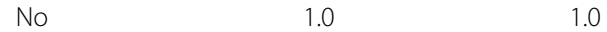

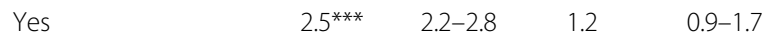

Owns a mobile telephone

$\begin{array}{lll}\text { No } & 1.0 & 1.0\end{array}$

$\begin{array}{lllll}\text { Yes } & 1.4^{* * *} & 1.2-1.5 & 1.8^{* *} & 1.2-2.7\end{array}$

Number of ANC visits

\begin{tabular}{ccc}
0 & 1.0 \\
$1+$ & $4.2^{* * *}$ & $3.8-4.7$ \\
\hline AOR Adjusted odds ratio *** & $p<0.001,{ }^{* *} p<0.01, * 0<0.05$
\end{tabular}

In our study, adolescents age 15-19 and young adults age 20-24 were less likely to be tested, for both genders. The same observation had been made by other studies. Adolescents are less likely to use HIV testing services [8, 14, 21-24]. Several explanations can be advanced. The level of HIV knowledge among youth in sub-Saharan Africa is very low $[8,17,25-27]$ and their use of HIV testing services (HTS) is very poor [21, 25]. This is a problem because teens become sexually active early $[21,25]$ and are thus more exposed to sexually transmitted infections. In addition, high levels of stigma can be another main cause [14, 17]. HIV-related stigma and discrimination seriously impede efforts to effectively combat the HIV pandemic. Fear of discrimination often prevents people from undergoing $\mathrm{HCT}$ or from disclosing their HIV status [28].

To address this gap, we advocate strengthening HIV testing campaigns in secondary schools as well as increasing school-based educational programs. The use of urinary or saliva rapid HIV tests can be promoted as they are associated with HIV testing [29, 30]. Some studies among youth in the African region showed that older youth (2024 years) had higher odds of HIV testing than younger youth $(15-19$ years) $[8,21]$. Another challenge could be consent for adolescents under age 18. In Senegal, the age of majority is 18 , so adolescents under age 18 may not attend HTS. Another explanation of this relationship is that older age confers more economic and social power, which is why among both women and men older people are more likely to be screened for HIV.

Another factor is that after age 25 most women and men are married. With pregnancy, women gain access to antenatal care services and have more opportunities to be tested. Senegal adopted universal HIV testing 
during pregnancy as recommended by WHO [6]. In line, as expected, our study found that women with at least one ANC visit had four times the odds of having an HIV test compared with those who had no ANC visit or did not have a birth in the last 5 years.

Women living in the West zone are more likely to be tested than women in the other zones of Senegal. The West zone includes the regions of Dakar and Thiès-the capital city and its closest region-so many health services are concentrated there, and people also have better access to the media and greater economic power. This leads to increased opportunities for HIV testing. Also, these areas are predominantly urban. However, the results for men are in the opposite direction than women. Men living in North and South-East zones are more likely to be tested. The reason behind this discrepancy has to be examined more closely. However, studies show that, regardless of gender, people living in urban areas are more likely to be tested for HIV compared with their counterparts in rural areas [7, 13, 24, 31]. HIV testing strategies must target HIV hot-spot regions, specifically in the South-East zone.

Our study highlights how difficult it is for health promotion programs to reach the poorest sections of the population. Even though HIV testing in Senegal is free, testing rates increase with educational level and wealth for both men and women. These findings are consistent with previous reports $[7,9,10,12,13,24,31,32]$. On average, the odds of having HIV testing are 6.3 times higher among men and 2.8 times higher among women with a high level of education compared with men and women with no education. Higher educational attainment is associated with more comprehensive knowledge of HIV and its prevention [32, 33]. Women deciding alone about their own health care are more likely to be tested for HIV compared with women for whom someone else is involved in decisions on their care, whether husbands/partners or other family members.

In agreement with studies in Ethiopia and Rwanda [7, 14], we found that media exposure increases the uptake of HIV testing. For many years now in Senegal, messages extolling the benefits of early detection and treatment have been distilled through the media, particularly on television and radio. However, these campaigns have shown their limits, while other strategies exist that can reach audiences directly. In our study both men and women show greater odds of HIV testing if they own a mobile phone. Since it appears that, regardless of gender, possession of a mobile phone is a predictor of HIV testing, strategies to reach men and women through their mobile phones should be developed and implemented.

STI status is another important determinant for HIV testing $[10,24,34]$. Our study did not allow us to draw this conclusion for women, however. Even though having any STI in the last 12 months was significantly associated with being tested for HIV among women, only $3.5 \%$ of women and $0.5 \%$ of men in our sample reported having any STI in the last 12 months. Since data obtained in the survey were self-reported, the findings could be biased.

In some studies, having two or more sexual partners in the past year is associated with knowledge of HIV status $[13,32]$. However, our study did not find this relationship. Instead, among both men and women not knowing the lifetime number of partners was found to be associated with HIV testing. This fact was more significant among women. Sometimes not knowing the number of partners is an indication of having many partners.

A comprehensive knowledge about HIV has been found to be a predictor of HIV testing [7, 8, 13]. Our study shows that men are slightly more knowledgeable about HIV compared with women, including awareness of mother-to-child transmission (MTCT). However, knowledge about MTCT was not found to be significantly associated with HIV testing while, curiously, knowledge of drugs to prevent MTCT was associated with testing.

Our study has some limitations. Causal inferences are limited by the cross-sectional and observational design of the study. Another limitation is the splitting dataset between men and women which might impact on estimates reliability. Also, key high-risk populations are not identified. No information was collected that would identify survey respondents as members of population groups such as sex workers and men having sex with men. These populations are known to be reluctant to report HIV testing [35-37]. This is related to sociocultural constraints that make these people hide their status fearing rejection and criminalization. HIV infection is often thought to be the result of personal sexual irresponsibility [38] and so is still looked upon as a punishment [39].

New approaches in HIV testing and counselling should be assessed. For Land and al., future diagnostics should incorporate advances in digital technology and mobile health to give REASSURED diagnostic systems [40]. One of these new approaches is HIV self-testing (HIVST), and has been proposed to reach people who are not accessing existing HIV testing services (HTS) such as men, young people and key population groups. Some studies provide more answers. A recent meta-analysis showed HIV self-testing (HIVST) doubled uptake of testing among men [36]. Some studies in Kenya pointed that, HST is feasible in a community level and accepted by the public $[41,42]$. So, HIVST can increase uptake and frequency of HIV testing. However, concerns remain about the sensitivity of the test, the lack of council and the need of confirmation after a positive HIV self-test. 
Despite these concerns, WHO supports the introduction of HIV self-testing as an additional approach to HIV testing services [43]. Nonetheless, our study is important in that it uses nationally representative population survey data. Moreover, it is the first major study on the subject in Senegal.

\section{Conclusion}

This study provides evidence that the HIV testing rate is low in Senegal and that differences in testing persist between men and women. The first UNAIDS " 90 " target for 2020 has not yet been reached. The main barriers to accessing HIV testing facilities concern problems in reaching men and youth, lack of education and information, low socioeconomic status, rural residence, and poor access to communication.

These findings have implications for policy and programs. Given the low uptake of HIV testing among men and youth, innovative strategies to reach the youngest group, teenagers, must be implemented by scaling up the task with community involvement and access to selftesting tools. Another strategy is scaling up access to HIV testing outside the capital city, especially among women. Furthermore, to address the gaps in knowledge about HIV, communication about HIV and its treatment should be reinforced and women empowered through providing more education and promoting incomegenerating activities. Also, more integration between HIV and other reproductive health programs must be realized.

\section{Abbreviations}

ANC: Antenatal care; AOR: Adjusted odds ratio; Cl: Confidence intervals; DHS: Demographic Health Survey; HIV/AIDS: Human immunodeficiency Virus/Acquired Immunodeficiency; HIVST: HIV self-testing; MTCT: Mother to child transmission; STI: Sexually transmitted infections; UNAIDS: United Nations Programme on HIV and AIDS; WHO: World Health Organization

\section{Acknowledgments}

We thank the DHSFellows Program facilitators, Wenjuan Wang, Shireen Assaf, Gadefaw Abeje Fekadu, and Kyaw Swa Mya, for their support throughout the DHS training. We also appreciate the invaluable comments from the 2019 Fellows that helped improve our research. We thank also Joy Fishel from ICF for her insightful review of our paper.

\section{Authors' contributions}

KS came up with the study idea. NAL, KDM and CTN analyzed the data. NAL and CTN conducted the background research. NAL and KDM wrote the draft paper. All authors reviewed and approved the final manuscript.

\section{Funding}

The research project is funded by the USAID through the DHS Fellows program implemented by ICF International. The DHS Program assists countries worldwide in the collection and use of data to monitor and evaluate population, health, and nutrition programs. During the 2019 DHS Fellows, facilitators from ICF help to analyze the data and during the writing process.

\section{Availability of data and materials}

The datasets analyzed during the current study are publicly available upon request at https://dhsprogram.com/data/available-datasets.cfm.

\section{Ethics approval and consent to participate}

The 2017 Senegal Demographic Health Survey (DHS) was approved by the National Ethics Committee (CNERS). The survey also obtained the visa of the Committee of Ethics (Institutional Review Board) of ICF. The informed consent obtained from all participants was written.

Consent for publication

Not applicable.

\section{Competing interests}

The authors declare that they have no competing interests.

\section{Author details}

${ }^{1}$ Clinic of Infectious and Tropical Diseases, Fann National University Hospital, PO: 5035-Fann, Dakar, Sénégal. ²Parasitology-Mycology Service, Medecine Faculty, Cheikh Anta Diop University, PO: 5005-Fann, Dakar, Sénégal.

${ }^{3}$ Division for Fight Against HIV and Sexually Transmitted Infections, Ministry of Health, Dakar, Sénégal.

Received: 27 August 2019 Accepted: 20 December 2019

Published online: 31 December 2019

\section{References}

1. UNAIDS. UNAIDS data 2018. Jt U N Programme HIVAIDS; 2018. p. 376 Available from: http://www.unaids.org/en/resources/documents/2018/ unaids-data-2018

2. HIV/AIDS National Council of Senegal. Senegal: HIV/AIDS national strategic plan 2018-2022. Senegal: CNLS; 2018.

3. National Statistic and Demographic Agency of Senegal, ICF. Senegal: Continous-EDS 2017. Rockville: ANSD and ICF International; 2018. Available from: http://www.ansd.sn/ressources/rapports/Rapport\%20Final\%20EDS\%2 02017.pdf

4. Insight Start Study Group. Initiation of antiretroviral therapy in early asymptomatic HIV infection. N Engl J Med. 2015;373(9):795-807. https://doi. org/10.1056/NEJMoa1506816 Cited 29 Apr 2019

5. Declaration of Paris, UNAIDS P. Fast-track cities: ending the AIDS epidemic: UNAIDS; 2014. p. 90. Available from: https://www.unaids.org/sites/default/ files/media_asset/20141201_Paris_Declaration_en.pdf

6. World Health Organization. Consolidated guidelines on HIV testing services 2015. Geneva: World Health Organization; 2015. (WHO Guidelines Approved by the Guidelines Review Committee). Available from: http://www.ncbi.nlm. nih.gov/books/NBK316021/. Cited 6 Apr 2019

7. Molla G, Huruy A, Mussie A, Wondowosen T. Factors associated with HIV counseling and testing among males and females in Ethiopia: evidence from Ethiopian Demographic and Health Survey data. J AIDS Clin Res. 2015; 6:429. https://doi.org/10.4172/2155-6113.1000429.

8. Asaolu IO, Gunn JK, Center KE, Koss MP, Iwelunmor JI, Ehiri JE. Predictors of HIV testing among youth in sub-Saharan Africa: a cross-sectional study. PLoS One. 2016;11(10):e0164052.

9. Staveteig S, Croft TN, Kampa KT, Head SK. Reaching the "first 90": gaps in coverage of HIV testing among people living with HIV in 16 African countries. PLoS One. 2017;12(10):e0186316.

10. Takarinda KC, Madyira LK, Mhangara M, Makaza V, Maphosa-Mutsaka M, Rusakaniko S, et al. Factors associated with ever being HIV-tested in Zimbabwe: an extended analysis of the Zimbabwe demographic and health survey (2010-2011). PLoS One. 2016;11(1):e0147828.

11. Neilan AM, Dunville R, Ocfemia MCB, Salomon JA, Francke JA, Bulteel AJB, et al. The optimal age for screening adolescents and young adults without identified risk factors for HIV. J Adolesc Health. 2018;62(1):22-8 Available from: https://linkinghub.elsevier.com/retrieve/pii/S1054139X17304755. Cited 6 Apr 2019.

12. Agha S. Factors associated with HIV testing and condom use in Mozambique: implications for programs. Reprod Health. 2012;9:20.

13. Jean K, Anglaret X, Moh R, Lert F, Dray-Spira R. Barriers to HIV testing in Côte d'lvoire: the role of individual characteristics and testing modalities. PLoS One. 2012;7(7):e41353.

14. Musheke M, Ntalasha H, Gari S, McKenzie O, Bond V, Martin-Hilber A, et al. A systematic review of qualitative findings on factors enabling and deterring uptake of HIV testing in sub-Saharan Africa. BMC Public Health. 2013;13:220. 
15. Center KE, Gunn JKL, Asaolu IO, Gibson SJ, Ehiri JE. Contraceptive use and uptake of HIV-testing among sub-Saharan African women. PLoS One. 2016; 11(4):e0154213.

16. Abiodun O, Sotunsa J, Ani F, Jaiyesimi E. Knowledge of HIV/AIDS and predictors of uptake of HIV counseling and testing among undergraduate students of a privately owned university in Nigeria. BMC Res Notes. 2014;7:639

17. Nabukenya AM, Matovu JKB. Correlates of HIV status awareness among older adults in Uganda: results from a nationally representative survey. BMC Public Health. 2018;18(1) Available from: https://bmcpublichealth. biomedcentral.com/articles/10.1186/s12889-018-6027-z. Cited 6 Apr 2019.

18. Sambisa W, Curtis S, Mishra V. AIDS stigma as an obstacle to uptake of HIV testing: evidence from a Zimbabwean national population-based survey. AIDS Care. 2010;22(2):170-86

19. ICF International. Sampling and household listing manual demographic and health survey methodology. Calverton: ICF International; 2012. Available from: https://dhsprogram.com/pubs/pdf/DHSM4/DHS6_Sampling_Manual_ Sept2012_DHSM4.pdf

20. The DHS Program - DHS Questionnaires. Available from: https://dhsprogram com/What-We-Do/Survey-Types/DHS-Questionnaires.cfm. Cited 9 Dec 2019.

21. Sanga Z, Kapanda G, Msuya S, Mwangi R. Factors influencing the uptake of voluntary HIV counseling and testing among secondary school students in Arusha city, Tanzania: a cross sectional study. BMC Public Health. 2015;15:452.

22. MacPhail C, Pettifor A, Moyo W, Rees H. Factors associated with HIV testing among sexually active south African youth aged $15-24$ years. AIDS Care. 2009;21(4):456-67.

23. Van Handel M, Kann L, Olsen EO, Dietz P. HIV testing among US high school students and young adults. Pediatrics. 2016;137(2):e20152700.

24. Mahande MJ, Phimemon RN, Ramadhani HO. Factors associated with changes in uptake of HIV testing among young women (aged 15-24) in Tanzania from 2003 to 2012. Infect Dis Poverty. 2016:5(1):92.

25. Idele P, Gillespie A, Porth T, Suzuki C, Mahy M, Kasedde S, et al. Epidemiology of HIV and AIDS among adolescents: current status, inequities, and data gaps. J Acquir Immune Defic Syndr 1999. 2014;66(Suppl 2):S144-53.

26. Oginni AB, Adebajo SB, Ahonsi BA. Trends and determinants of comprehensive knowledge of HIV among adolescents and young adults in Nigeria: 2003-2013. Afr J Reprod Health. 2017;21(2):26-34 Available from: https://www.ajol.info/index.php/ajrh/article/view/160571. Cited 9 Apr 2019.

27. Alabi AD, Oke OA, Adedokun BO, Runsewe-Abiodun TI. Perception and practice of HIV/AIDS counseling and testing among secondary school adolescents in Ogun waterside local government area, Ogun state, Southwest Nigeria. Int Q Community Health Educ. 2018;38(3):175-80.

28. Kitara DL, Aloyo J. HIV/AIDS stigmatization, the reason for poor access to HIV counseling and testing (HCT) among the youths in Gulu (Uganda). Afr J Infect Dis. 2012;6(1):12-20.

29. Myers JE, Bodach S, Cutler BH, Shepard CW, Philippou C, Branson BM. Acceptability of home self-tests for HIV in New York city, 2006. Am J Public Health. 2014;104(12):e46-8 Available from: https://ajph.aphapublications.org/ doi/abs/10.2105/AJPH.2014.302271. Cited 9 Apr 2019.

30. Nangendo J, Obuku EA, Kawooya I, Mukisa J, Nalutaaya A, Musewa A, et al. Diagnostic accuracy and acceptability of rapid HIV oral testing among adults attending an urban public health facility in Kampala, Uganda. PloS One. 2017;12(8):e0182050.

31. Muhinda J, Pazvakawambwa L. HIV testing among women in Namibia: patterns and determinants. Biomed J Sci Tech Res. 2017;1(3) Available from: http://biomedres.us/fulltexts/BJSTR.MS.ID.000248.php. Cited 9 Apr 2019.

32. Peltzer K, Matseke G, Mzolo T, Majaja M. Determinants of knowledge of HIV status in South Africa: results from a population-based HIV survey. BMC Public Health. 2009;9(1):174. https://doi.org/10.1186/1471-2458-9-174 Cited 9 Apr 2019.

33. Owusu S. Trends and determinants of comprehensive knowledge of HIV Aids among Ghanaians based on Ghana demographic health surveys 19982014: University of Ghana; 2018. Available from: http://ugspace.ug.edu.gh/ handle/123456789/26571. Cited 9 Apr 2019

34. Swenson RR, Rizzo CJ, Brown LK, Payne N, DiClemente RJ, Salazar LF, et al. Prevalence and correlates of HIV testing among sexually active African American adolescents in 4 US cities. Sex Transm Dis. 2009;36(9):584-91 Available from: https://insights.ovid.com/crossref?an=00007435-20090900000010. Cited 6 Apr 2019
35. Figueroa C, Johnson C, Verster A, Baggaley R. Attitudes and acceptability on HIV self-testing among key populations: a literature review. AIDS Behav. 2015;19(11):1949-65.

36. Johnson CC, Kennedy C, Fonner V, Siegfried N, Figueroa C, Dalal S, et al. Examining the effects of HIV self-testing compared to standard HIV testing services: a systematic review and meta-analysis. J Int AIDS Soc. 2017;20(1): 21594.

37. Tun W, Vu L, Dirisu O, Sekoni A, Shoyemi E, Njab J, et al. Uptake of HIV selftesting and linkage to treatment among men who have sex with men (MSM) in Nigeria: a pilot programme using key opinion leaders to reach MSM. J Int AIDS Soc. 2018:21(Suppl 5):e25124.

38. Wolfe WR, Weiser SD, Leiter K, Steward WT, Percy-de Korte F, Phaladze N, et al. The impact of universal access to antiretroviral therapy on HIV stigma in Botswana. Am J Public Health. 2008;98(10):1865-71.

39. Makoae LN, Portillo CJ, Uys LR, Dlamini PS, Greeff M, Chirwa M, et al. The impact of taking or not taking ARVs on HIV stigma as reported by persons living with HIV infection in five African countries. AIDS Care. 2009;21(11): 1357-62.

40. Land KJ, Boeras DI, Chen X-S, Ramsay AR, Peeling RW. REASSURED diagnostics to inform disease control strategies, strengthen health systems and improve patient outcomes. Nat Microbiol. 2019;4(1):46-54.

41. Mugo PM, Micheni M, Shangala J, Hussein MH, Graham SM, Rinke de Wit TF, et al. Uptake and acceptability of oral HIV self-testing among community pharmacy clients in Kenya: a feasibility study. PloS One. 2017;12(1):e0170868.

42. Heard AC, Brown AN. Public readiness for HIV self-testing in Kenya. AIDS Care. 2016;28(12):1528-32 Available from: https://www.ncbi.nlm.nih.gov/ pmc/articles/PMC5062035/. Cited 24 Nov 2019.

43. World Health Organization. Guidelines on HIV self-testing and partner notification: supplement to Consolidated guidelines on HIV testing services. 2016.

\section{Publisher's Note}

Springer Nature remains neutral with regard to jurisdictional claims in published maps and institutional affiliations.

Ready to submit your research? Choose BMC and benefit from:

- fast, convenient online submission

- thorough peer review by experienced researchers in your field

- rapid publication on acceptance

- support for research data, including large and complex data types

- gold Open Access which fosters wider collaboration and increased citations

- maximum visibility for your research: over $100 \mathrm{M}$ website views per year

At $\mathrm{BMC}$, research is always in progress.

Learn more biomedcentral.com/submissions 